\title{
Mechanical Behavior of non Veneered Three Unit Fixed Partial Dentures of Alumina-Zirconia Under Cyclic Load in Wet Environment
}

\author{
Flavio Teixeira da Silva*, Rafael Andreiuolo ${ }^{\text {b }}$, Carlos Eduardo Sabrosa ${ }^{\mathrm{b}}$ \\ ${ }^{a}$ Programa de Engenharia Metalúrgica e de Materiais - PEMM - COPPE \\ Universidade Federal do Rio de Janeiro - UFRJ \\ Centro de Tecnologia, Bloco F, sala F-210, 21941-972 Rio de Janeiro - RJ, Brazil \\ ${ }^{\mathrm{b}}$ Universidade Veiga de Almeida
}

Received: November 6, 2009; Revised: December 10, 2009

\begin{abstract}
The aim of this study was to evaluate the fatigue behavior in wet environment of a ZTA three unit FPDs processed via CAD-CAM. Thirty four three unit FPDs (In-Ceram ${ }^{\circledR}$ Zirconia BZ blanks) were grinded through a CEREC In-Lab equipment followed by glass infiltration and sandblasting. Those frameworks were then submitted to different number of load cycles $(400 \mathrm{~N}, 1 \mathrm{~Hz})$. The FPDs that did not fractured by fatigue were submitted to a bending test in order to determine the influence of load cycling on its residual load. The non-parametric Kruskal-Wallis of those tests have shown with a $95 \%$ confidence, that there is a clear relation between the number of load cycles and its residual load. The fracture mode most frequently encountered on those FPDs was through the distal connector.
\end{abstract}

Keywords: alumina-zirconia, CAD-CAM, three unit FPD, cyclic fatigue

\section{Introduction}

For decades porcelain-fused-to-metal has been the choice for fixed partial dentures (FPDs). Because of the inherent aesthetic disadvantage of metallic frameworks, new ceramic systems were introduced in the market. However, ceramics being brittle, with low fracture toughness and relatively low flexural strength limited its use as all-ceramic FPDs. These limitations became more critical for posterior teeth, where the mastication forces can reach loads higher than $500 \mathrm{~N}^{1}$.

The need to enhance the mechanical properties mainly at the high stress regions of the FPDs, suggest the use of zirconia based ceramics. Zirconia is a well-known polymorph that occurs in three forms: monoclinic, tetragonal and cubic ${ }^{2}$. The remarkable mechanical properties of zirconia is mainly due to its tetragonal to monoclinic phase transformation, which can be induced by external stresses (mechanical or thermal), generates compressive stresses at its surface inhibiting crack propagation. This mechanism explains why fracture toughness of zirconia toughened alumina (ZTA) is higher than alumina ceramics. Furthermore, transformation toughening is not the only mechanism acting in zirconia-based ceramics; microcracking, contact shielding and crack deflection can also contribute to the toughening of those ceramics ${ }^{3}$.

One of the most representative zirconia-based dental ceramics is In-Ceram ${ }^{\circledR}$ Zirconia (Vita Zahnfabrik, Bad Säckingen, Germany). It was developed by adding $33 \mathrm{~mol}(\%)$ of partially stabilized zirconia $\left(12 \mathrm{~mol}(\%) \mathrm{CeO}_{2}\right)$ to alumina, in an attempt to combine the high toughness of zirconia to the hardness and higher translucency of alumina $^{3,4}$. Alumina-zirconia blanks (BZ) processed by CAD-CAM are grinded in a CEREC In-Lab equipment followed by glass infiltration and sandblasting. Frameworks processed via CAD-CAM in relation to the tradicional slip casting are thought to have better mechanical properties due to its more consistent processing 5 .

Although much work has been published related to the strength and fracture toughness of glass-infiltrated alumina/zirconia dental ceramic $^{3,6,7}$, little is known about their behavior under cyclic load in wet environment. Under stress, the glass phase may be submitted to stress corrosion, leading to increased crack propagation. On the other hand, glass-free systems such as dense $\mathrm{ZrO}_{2}$, display an excellent long-term stability.

The main aim of this study was to evaluate the influence of mechanical grinding and cyclic load in wet environment on the mechanical strength of non-veneered three unit FPDs alumina-zirconia-glass composites. The conditions of fatigue tests were established ( $400 \mathrm{~N}$ in water, $1 \mathrm{~Hz}$ ). The frameworks that did not fractured by fatigue were submitted to a bending test, in order to determine the influence of load cycle on its residual strength. In order to estimate the tensile stress at the connector, a simulation of stress distribution is presented based on materials resistance concepts.

\section{Materials and Methods}

The chemical analysis of In-Ceram ${ }^{\circledR}$ Zirconia (BZ blanks) and of the infiltration frit are shown in Table 1. A dental model with a missing molar tooth was used to prepare a three unit FPD (Figure 1). The low expansion master model (Silky-Rock Type IV, Whip Mix Corporation), addition silicone (Express ${ }^{\circledR}$ Putty (3M ESPE) and Aquasil Ultra XLV Fast Set) was used to mold the region of the missing tooth. After impressions of the master model, thirty-four epoxy resin molds were obtained.

The master model was laser scanned in a CEREC 3 In-Lab machine to the following dimensions; $0.5 \mathrm{~mm}$ thickness, $4.0 \times 3.5 \mathrm{~mm}$ mesial connectors and $3.5 \times 3.5 \mathrm{~mm}$ distal connectors. The occlusal anatomy of the pontic was especially designed to stabilize the loading sphere during the fatigue tests, as shown in Figure 2.

Thirty-four three unit FPDs were wet grinded with two diamond burs (one cylindrical and one conical) in a CEREC In-Lab equipment during approximately 60 minutes. The FPDs removed from the unused blank was submitted to glass infiltration $\left(1100{ }^{\circ} \mathrm{C}\right.$ for 360 minutes followed by slow cooling inside the furnace). The infiltrated frameworks were submitted to sandblasting ( $\mathrm{Al}_{2} \mathrm{O}_{3} 25 \mu \mathrm{m}, 3$ bar), in order to remove the excess glass, and after cemented to the resin dies with 
Table 1. Chemical composition of alumina-zirconia (BZ blanks) and of the infiltration frit (Vita Zahnfabrik, Bad Säckingen, Germany).

\begin{tabular}{|c|c|c|}
\hline Oxides & BZ blank wt. (\%) & Infiltration frit wt. (\%) \\
\hline $\mathrm{Al}_{2} \mathrm{O}_{3}$ & 67 & $14-18$ \\
\hline $\mathrm{ZrO}_{2}\left(12 \mathrm{~mol} \% \mathrm{CeO}_{2}\right)$ & 33 & - \\
\hline $\mathrm{SiO}_{2}$ & - & $14-18$ \\
\hline $\mathrm{B}_{2} \mathrm{O}_{3}$ & - & $11-15$ \\
\hline $\mathrm{TiO}_{2}$ & - & $2-7$ \\
\hline $\mathrm{La}_{2} \mathrm{O}_{3}$ & - & $25-30$ \\
\hline $\mathrm{CeO}_{2}$ & - & $6-10$ \\
\hline $\mathrm{CaO}$ & - & $4-8$ \\
\hline $\mathrm{ZrO}_{2}$ & - & $1-4$ \\
\hline $\mathrm{Y}_{2} \mathrm{O}_{3}$ & - & $2-6$ \\
\hline
\end{tabular}
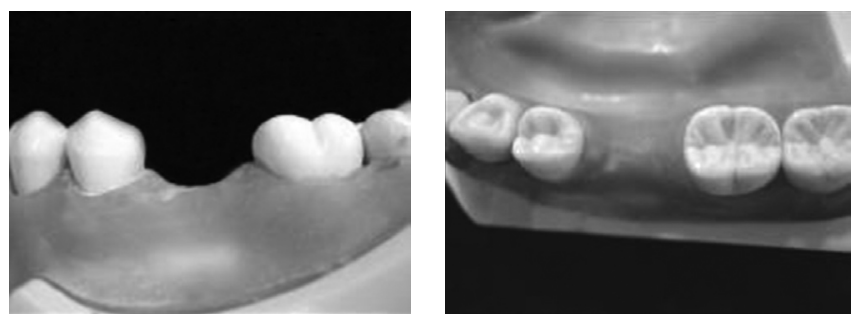

Figure 1. Model used to produce the three unit FPDs (inferior second premolar to second molar)

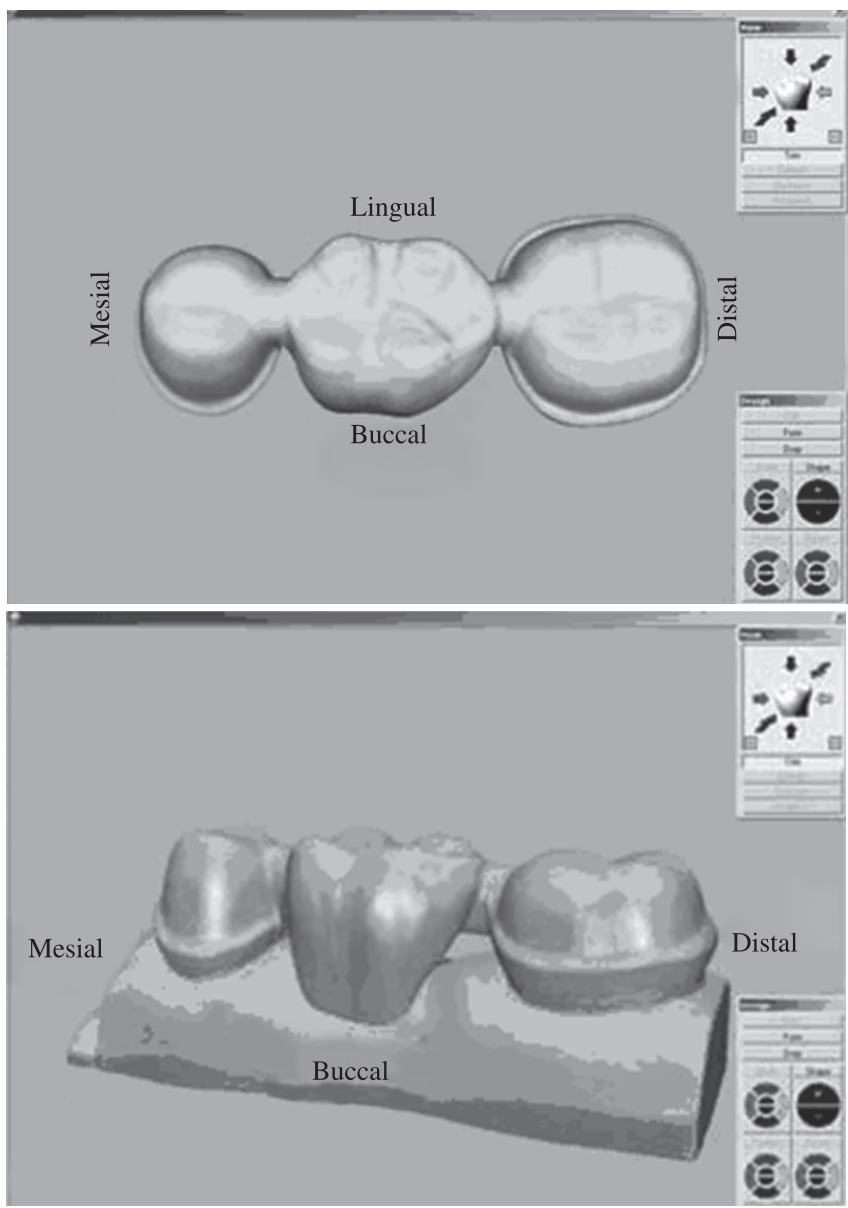

Figure 2. Three unit FPD digitalization (CEREC 3 In/Lab).
Rely-X Unicem (3M ESPE) resin cement at room temperature for 10 minutes with a constant load of $25 \mathrm{~N}$ applied at its pontic center. Light curing was performed for 20 seconds, mainly through the buccal and lingual sides of the abutment teeth.

The couple FPDs/epoxi mold was then inserted on a pneumatic cyclic load testing machine developed by Dr. Richard Pober from Boston University (Figure 3). The applied load (F) was calculated indirectly through the expression $\mathrm{F}=\mathrm{P}_{\text {air }} \times \mathrm{A}$, where $\mathrm{P}_{\text {air }}$ is the air pres-

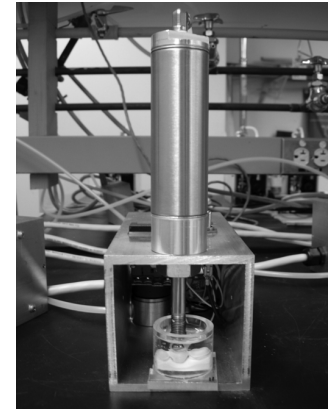

(a)

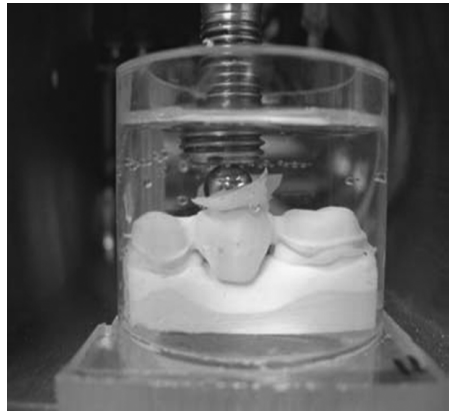

(b)
Figure 3. a) Cyclic fatigue test equipment. b) Detail of the three unit FPD immersed in water during cyclic test, showing the teflon sheet between the steel ball and the framework.

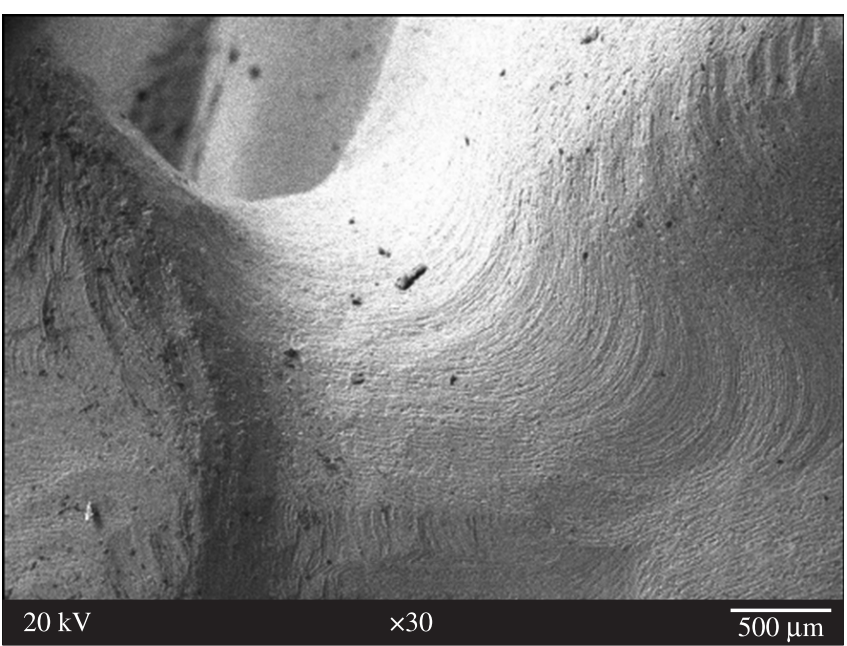

(a)

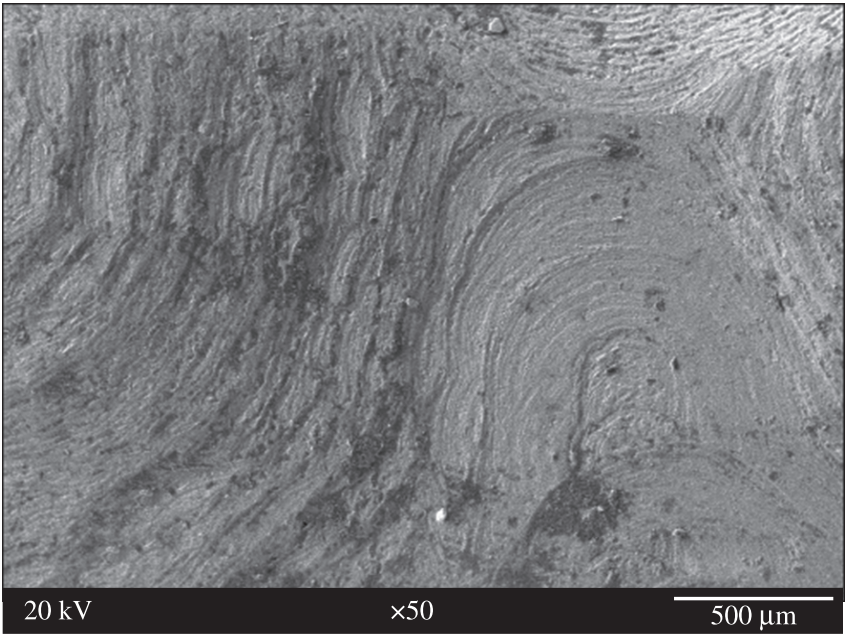

(b)

Figure 4. Surface marks of two alumina-zirconia FPDs after machining. a) Smooth surface and b) rough surface. 
sure that flows through a solenoid with an area A. The load frequency $(1 \mathrm{~Hz})$ was dictated by the opening and closure of the solenoid. The FPDs were submitted to $400 \mathrm{~N}$ for different number of load cycles through a $8.5 \mathrm{~mm}$ diameter hardened steel sphere located over the pontic center. In order to prevent possible failure by Hertzian cone crack, the ball contact was separated from the central fossa by a teflon sheet, in the same manner as reported by Kelly ${ }^{13}$.

The frameworks that did not fractured under load cycling were submitted to a bending test in order to determine its residual strength. Scanning electron microscopy (SEM), X-ray diffraction (XRD) and atomic force microscopy (AFM) were used to characterize the morphology and phase transformations after grinding and after fracture.

\section{Results and Discussion}

The first step of this work was to evaluate the degree of homogeneity of the as received partial sintered alumina-zirconia blanks (BZ). Scanning electron microscopy of several blanks have shown that they were very homogeneous. The second step was to evaluate the dispersion of the depth of the milling marks immediately after grinding. It was observed that the great majority of the milled frameworks presented a smooth surface (Figure 4-a). Some rougher surfaces probably due to the excess number of frameworks milled with the same bur ${ }^{8}$ were discarded (Figure 4-b).

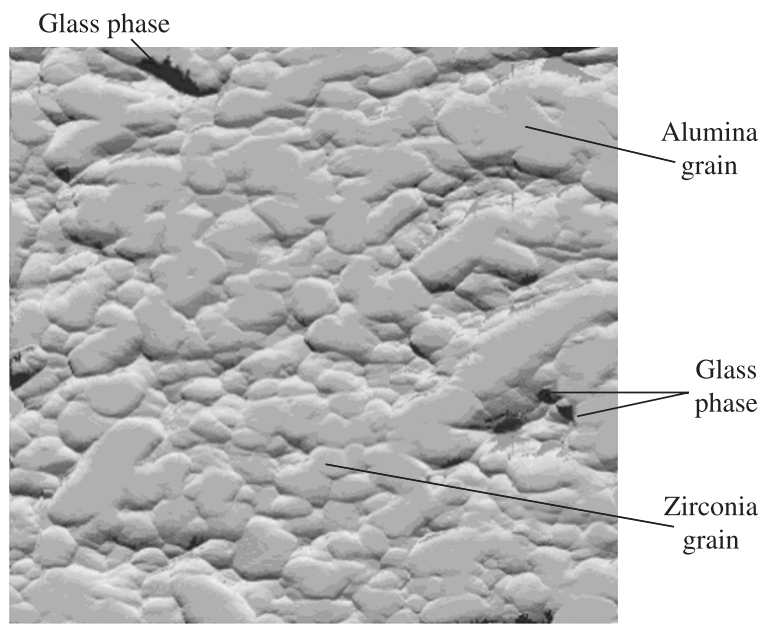

Figure 5. AFM image of a glass infiltrated alumina zirconia matrix.

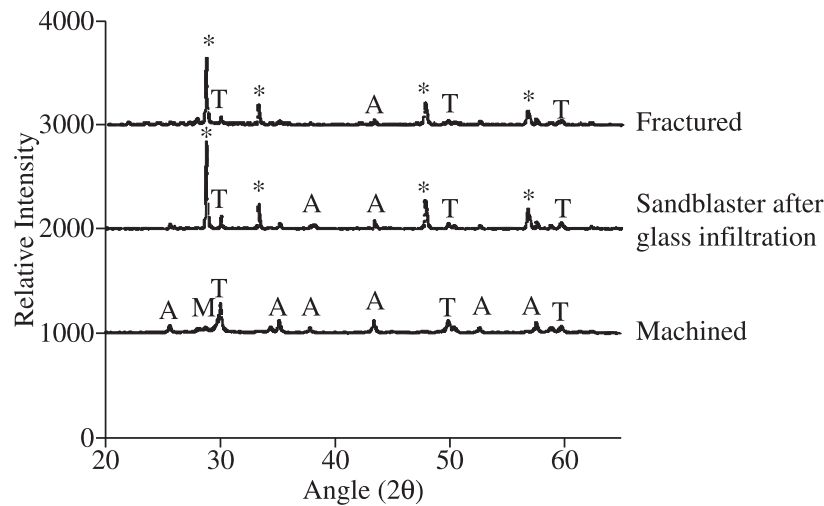

Figure 6. X-ray diffraction of the alumina-zirconia submitted to different processing steps: After wet machining, after glass infiltration and sandblasting and after fracture. A - alumina; $\mathrm{M}$ - monoclinic zirconia; $\mathrm{T}$ - tetragonal zirconia; $* \mathrm{CeO}_{2}$ crystals.
The second step was to evaluate the degree of homogeneity of the FPDs after glass infiltration. Figure 5 shows an AFM image after glass infiltration. It can be seen that the glass phase was not homogeneously distributed in the alumina-zirconia matrix.

Figure 6 shows the X-ray diffraction of the as received BZ blank and of a FPD immediately after grinding and after glass infiltration. The decrease in the relative intensity of monoclinic zirconia after wet milling was due to the monoclinic-tetragonal phase transformation related to the mechanical and thermal stresses during grinding. In the glass infiltrated FPD the small monoclinic peak vanished and appeared strong new peak identified as ceria crystals. This result is an indication of the relatively low solubility of ceria in the glass phase.

Some cyclic load tests in ceramic FPDs were due to De Long and Douglas ${ }^{9}$ Munz and Fett ${ }^{10}$ and Studard et al. ${ }^{11,12}$. Studart et al. ${ }^{12}$ proposed a method to estimate the lifetime of two, three and four FPDs based on Weibull statistics (Figure 7), where Pf is the cummulative probability of failure by fatigue, $\mathrm{N}_{\mathrm{f}}$ the number of cycles to fracture, $\mathrm{N}_{\mathrm{f}, 0}$ the number of cycles for $63 \%$ cumulative probability of failure and $\mathrm{m}^{*}$ the Weibull modulus which is related to the reliability of experimental data. Equation (1).

$$
\ln \ln \left(1 / 1-\mathrm{P}_{\mathrm{f}}\right)=\mathrm{m} * \operatorname{lnN}_{\mathrm{f}} \cdot \mathrm{m} * \operatorname{lnN}_{\mathrm{f}, 0}
$$

Due to the differences in the parameters of the cyclic load test, it was impossible to compare the lifetime of the present work with the one from Studart et al. ${ }^{12}$. In the present work, the number of cycles to fracture by fatigue varied in the range $10^{2}-10^{5}$ cycles. The relatively high dispersion in lifetime was probably due to residual stresses during load cycling, mainly induced by processing (grinding, sandblasting and non-homogeneous glass infiltration).

At high number of load cycles in wet environment, the rupture of the $\mathrm{Si}-\mathrm{O}$ bonds forming $\mathrm{Si}-\mathrm{OH}$ bonds in the glass phase may promote the nucleation of microcracks mainly at the connector region. In order to reduce those stresses, smooth curvature and enlarged connector size are two possible alternatives. Unfortunately, connector dimen-

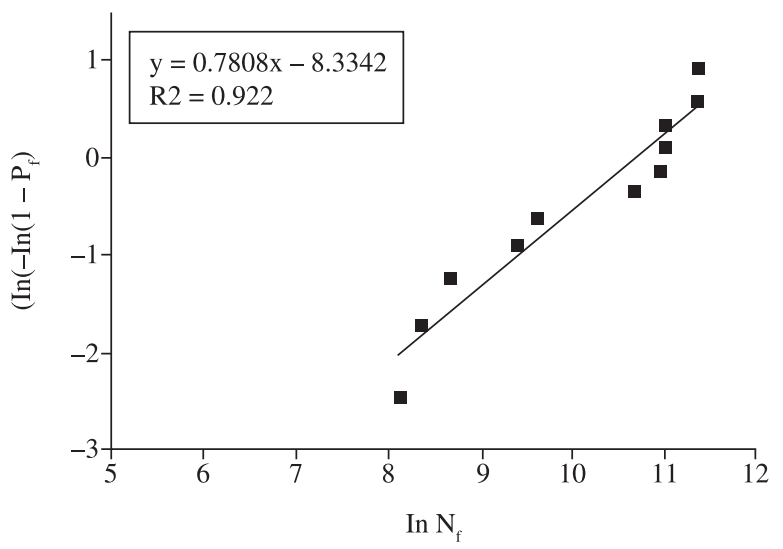

Figure 7. Weibull distribution for lifetime of BZ frameworks (400 N in water, $1 \mathrm{~Hz}$ ).
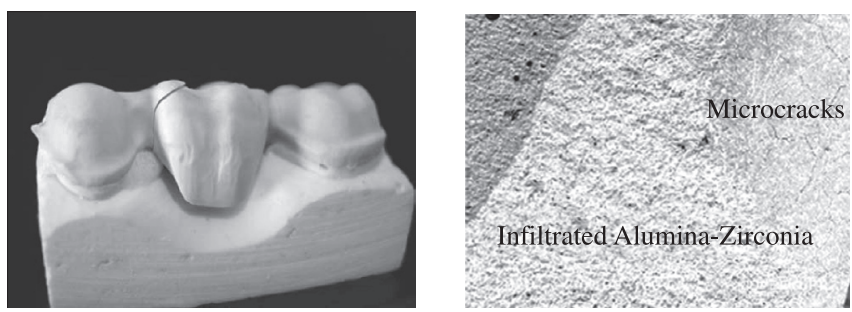

Figure 8. a) Three unit FPD fractured by fatigue after 85.000 cycles; and b) Microcracks can be seen at the distal connector from the same sample. 


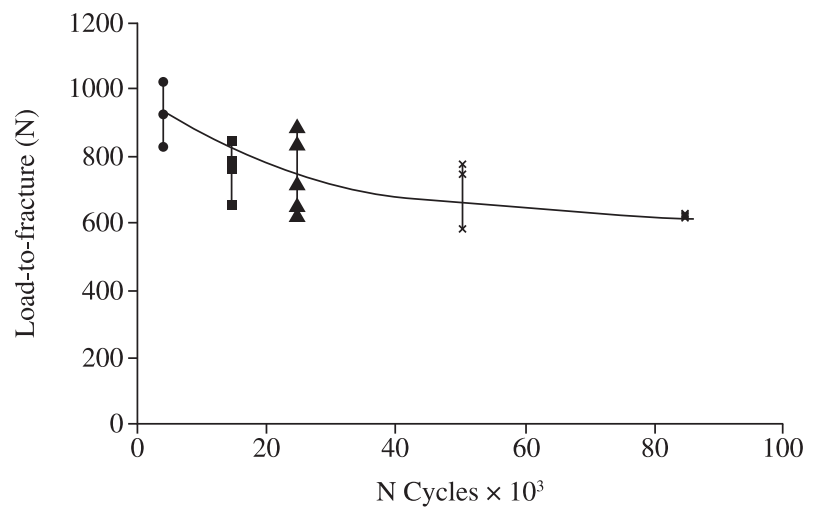

Figure 9. Load-to-fracture $X$ number of cycles for the frameworks that did not fractured by fatigue.
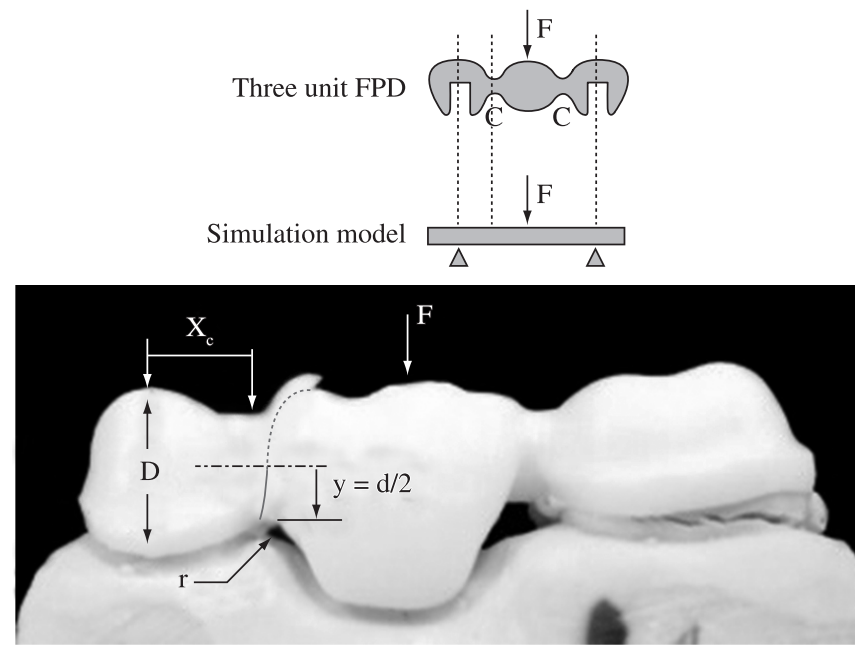

\begin{tabular}{|c|c|c|c|c|}
\hline $\mathrm{Xc}(\mathrm{m})$ & $\mathrm{D}(\mathrm{m})$ & $\mathrm{r}(\mathrm{m})$ & $\mathrm{r} / \mathrm{D}$ & $\mathrm{D} / \mathrm{d}$ \\
\hline 0.0030 & 0.0034 & 0.00058 & 0.171 & 3.0 \\
\hline
\end{tabular}

Figure 10. Simulation model of a three unit FPD. The letter $\mathrm{c}$ indicates the region of the highest tensile stresses. Magnification of the FPD - 3X.

sions, important for biologic and aesthetic reasons, are limited by its occlusal and gengival contacts ${ }^{14}$.

Figure 8 shows that fracture propagates obliquely from the maximum tensile stress at the connector to the maximum compressive stress at the pontic region. In the present work, 67\% of the FPDs fractured through the distal connector $(3.5 \times 3.5 \mathrm{~mm})$ and $33 \%$ through the mesial connector. $(3.5 \times 4.0 \mathrm{~mm})$. With a higher magnification, it can be seen microcracks at the connector region.

The frameworks that did not fractured by fatigue for different number of load cycles were submitted to a bending test in order to determine the influence of the number of load cycles on its residual strength. Figure 9 indicates a decrease in strength with the number of load cycles. Kruskal-Wallis test with $95 \%$ confidence indicated that this effect was statistically significant.

In order to estimate the range of tensile stresses at the connector for different axial loads applied at the pontic center, a similar simulation as reported by Studart et al. ${ }^{12}$ was developed by considering the three unit FPD as a cylindrical bar with a fillet, as shown in Figure 10. From the three unit FPD, the tensile stress at the connector could be estimated from the Equations (2) and (3).
Table 2. Estimated maximum tensile stress at the connector (MPa) for different axial loads $(\mathrm{N})$.

\begin{tabular}{cc}
\hline $\begin{array}{c}\text { Load-to-fracture } \\
(\mathrm{N})\end{array}$ & $\begin{array}{c}\text { Estimated maximum tensile } \\
\text { stress at the connector }(\mathrm{MPa})\end{array}$ \\
\hline 400 & 250 \\
600 & 370 \\
800 & 500 \\
1000 & 622 \\
\hline & \\
$\sigma_{\mathrm{c}}=\mathrm{M}_{\mathrm{c}} \cdot \mathrm{y} / \mathrm{I}$ & \\
$\sigma_{\mathrm{c}}=\mathrm{K} .16$. F. $\mathrm{x}_{\mathrm{c}} / \pi . \mathrm{d}^{3}$ &
\end{tabular}

where $\sigma_{c}$ represents the tensile stress at the connector, $M_{c}$ the moment applied to the connector, $y$ the distance between the neutral line and any point at the cross section of the bar $(y=d / 2)$ and I the inertia moment $\left(I=\bar{\omega}^{4} / 64\right)$. Substituting $M_{c}$ and $I$ in Equation 2, the maximum tensile stress could be estimated from Equation 3, for $\mathrm{y}=\mathrm{d} / 2$ and $\mathrm{x}$ $=\mathrm{x}_{\mathrm{c}} \cdot \mathrm{F}=400 \mathrm{~N}$ and $\mathrm{K}=1.6$ being the stress concentration factor ${ }^{15}$. Table 2 shows the estimated maximum tensile stress at the connector for different axial loads until fracture.

\section{Conclusions}

For cyclic load $(400 \mathrm{~N}, 1 \mathrm{~Hz})$ in wet environment, approximately $50 \%$ of the FPDs fractured by fatigue. This high dispersion could be related to several factors as mechanical grinding, stress concentration due to non-homogeneous glass distribution in the alumina-zirconia matrix and possibly stress corrosion of the glass phase.

Due to the complex stress distribution of the FPD, fracture begins at the high tension stress at the connector, deviating further to a region near the pontic center.

FPDs that did not fractured by fatigue submitted to a bending test until fracture, have shown a decrease in its residual strength with an increase in the number of load cycles. As expected, this decrease was more pronounced at high number of load cycles.

\section{Acknowledgements}

To Dr. Richard Pober and to Dr. Russel Giordano for the laboratorial and financial support at Boston University, USA.

To Dr. Tsuneharu Ogasawara, PEMM-COPPE/UFRJ, head of PRONEX PROJECT (Dental Ceramics - Process E-26/171204/2003), for the financial support.

To Dr. Rogério Machado researcher from the INMETRO, for the X-ray diffractions.

\section{References}

1. Pallis K, Griggs JA, Woody RD, Guillen GE, Miller AW. Fracture resistance of three all-ceramic restorative systems for posterior applications. Journal of Prosthetic Dentistry. 2004; 91(6):561-9.

2. Piconi C, Maccauro G. Zirconia as a ceramic biomaterial. Review. Biomaterials. 1999; 20(1):1-25.

3. Guazzato M, Albakry M, Simon PR, Swain MV. Strength, fracture toughness and microstructure of a selection of all-ceramic materials. Part II. Zirconiabased dental ceramics. Dental Materials. 2004; 20(5):449-456.

4. Guazzato M, Albakry M, Quach L, Swain MV. Influence of surface and heat treatments on the flexural strength of a glass-infiltrated alumina/zirconiareinforced dental ceramic. Dental Materials. 2005; 21(5):454-63.

5. Giordano R. CAD/CAM: An Overview of Machines and Materials. Journal of Dental Technology. 2003; 9:20-30. 
6. Tinschert J, Natt G, Mautsch W, Augthun M, Spiekermann H. Fracture resistance of lithium disilicate, alumina, and zirconia-based three-unit fixed partial dentures: A laboratory study. International Journal of Prosthodontics. 2001; 14(3):231-8.

7. Chong KH, Chai J, Takahashi Y, Wozniak W. Flexural strength of InCeram alumina and In-Ceram zirconia core materials. International Journal of Prosthodontics. 2002; 15(2):183-8.

8. Yara A, Ogura H, Shynia A, Tomita S, Miyazaki T, Suga Y et al. Durability of diamond burs for the fabrication of ceramic crowns using dental CAD/ CAM. Dental Materials Japan. 2005; 24(1):134-139.

9. De Long R, Douglas WH. An artificial oral environment for testing dental materials. IEEE Transactions Biomedical Enginnering.1991; 38(4):339-345.

10. Munz D, Fett T. Ceramics: mechanical properties, failure behavior, material selection. Berlin: Springer-Verlag; 1999.
11. Studard AR, Filser F, Kosher P. Fatigue of zirconia under cyclic loading in water and its implication for the design of dental bridges. Dental Materials. 2007; 23(1):106-114.

12. Studard AR, Filser F, Kosher P, Gaukler LJ. In vitro lifetime of dental ceramics under cyclic loading in water. Biomaterials. 2007; 28(7):2695-2705

13. Kelly JR. Clinically relevant approach to failure testing of all-ceramic restorations. Journal of Prosthetic Dentistry. 1999; 81(6):652-661.

14. Oh WH, Gotzen N, Anusavice KJ. Influence of connector design on fracture probability of ceramic FPDs. Journal of Dental Research. 2002; 81:623-627.

15. Collings JA. Failure of materials and mechanical design: analysis, prediction and prevention. New York: John Wiley and Sons; 1981. 
